\title{
Recycling High-Density Polyethylene (HDPE) into Construction Materials as a key step in Plastic Waste Reduction: Case of Kigali City
}

\author{
INGABIRE Dominique $^{1, \mathrm{a}^{*}}$, NTIHEMUKA Fulgence ${ }^{1, \mathrm{~b}}$, MUGABO GITARE $^{1, \mathrm{c}}$, ISABANE Remy Serge $^{1, \mathrm{~d}}$ and \\ TURATIMANA Théogene ${ }^{1, \mathrm{e}}$ \\ ${ }^{1}$ University of Rwanda, College of Science and Technology, School of Engineering, Department of Civil, Environmental and \\ Geomatics Engineering, Rwanda \\ a d.ingabire@ur.ac.rw or dominique.ingabire@gmail.com, ${ }^{\mathrm{b}}$ fulgentus@yahoo.fr,${ }^{\mathrm{c}}$ gitmug5@gmail.com, \\ dremmybebes@gmail.com, ${ }^{\mathrm{d}}$ theoturatimana@gmail.com
}

*Corresponding author: Email: dominique.ingabire@ gmail.com or d.ingabire@ur.ac.rw, Phone: (+250) 783827871

\begin{abstract}
Plastic wastes are increasing at an alarming rate and adversely affecting environment as they are not easily degraded. Worse still, roads along with parking yards have significantly shorter design life and so do other alternative road paving techniques such as reinforced concrete slabs and concrete paving blocks (developing countries). Owing to these challenges, this research aimed to minimize the quantity of plastic wastes dumped in Kigali landfills by recycling it into construction materials while considering both economic and environmental benefits. Specific objectives included to maximize the use of post-consumer plastic waste and produce alternative eco-friendly building products.

Similarly, the research aimed at determining the melting point and subsequent effects of temperature on high density polyethylene (HDPE) as well as determining the mix ratio of the material components that gives the highest compressive strength. Finally, the research aimed at assessing the performance of paving material made of sand and plastic wastes.

In order to achieve the stated objectives, three samples per data point were prepared and quantity of sand content was varying by $1: 3 ; 1: 4 ; 1: 5$ respectively while keeping plastic content constant. The samples were placed in mould of dimension 100,65 mm in diameter and height respectively where they cooled and set. Compaction was done using standard method. Afterwards, the respective samples were tested for compressive strength and water absorption. Compressive strength test showed the values of $21.73 \mathrm{~N} / \mathrm{mm}^{2}, 26.15 \mathrm{~N} / \mathrm{mm}^{2}, 4.79 \mathrm{~N} / \mathrm{mm}^{2}$ before heat exposure and $17.79 \mathrm{~N} / \mathrm{mm}^{2}, 22.37 \mathrm{~N} / \mathrm{mm}^{2}, 3.52 \mathrm{~N} / \mathrm{mm}^{2}$ after exposure to $35{ }^{0} \mathrm{C}$ for 12 hours for the pavers in HDPE and sand mix ratio of 1:3, 1:4 and 1:5 respectively. Water absorption test showed an average value of $0.052 \%$ which is lower compared to the cement concrete made pavers.
\end{abstract}

The research concluded that if made and put into use, these pavers will not only reduce construction costs especially those for repairs, but also assist in environmental conservation. Roads and parking yards will be cheaply constructed, and with the increased durability, accessibility will be improved and economic growth boostered.

Keywords: HDPE, wastes, recycle, paver, compressive strength

\section{Introduction}

High-Density Polyethylene (HDPE) are among those plastics category which can be recycled. They are very slow to undergo microbial degradation [1] and can stay intact in the environment for up to centuries [2]. Production of HDPE and other plastics is steadily increasing year by year because of their demand in daily life activities [3]. In general, the increase in worldwide consumption rate for plastics; the 
synthetic long chains of polymers [4]; is about $12 \%$ per year while plastic production is 0.15 billion tons per year on a global scale $[5,6,7,8]$. These polymers generally contain carbon and hydrogen with, sometimes, other elements such as oxygen, nitrogen, chloride or fluoride $[8,9]$. On the other hand, worldwide plastic wastes accumulation in the environment is 25 million tons per year [5,7]. Despite the commonly used plastic wastes management practices which include landfilling or incineration, these have adverse effects on environment with production of microplastics and/or toxic gases. Recycling of plastics proves to be a more reliable solution to reduce them from the environment though its rate is still low. When plastics are recycled into construction materials, sand has the capability of improving their mechanical properties such as rigidity and characteristic strength $[10,11]$. It is noted that modulus of rigidity and viscosity of polymer sand nanocomposite (PCN) increases with the increase in sand content. Another study showed that clay particles; due to their large surface area; have the potential of increasing modulus of rigidity $(\mathrm{G})$ and viscosity $(\eta)$ of PCN though sand was found to better bind with plastics which makes it a promising solution when recycled into construction materials especially for the case of HDPE. In line with this, recycling HDPE plastics into construction materials will tremendously reduce the amount of such wastes that would rather accumulate in landfills, open environment, lakes, rivers or oceans.

\section{Materials and methods}

\subsection{Methodology}

As mentioned in our literature, different methods have been used while recycling plastic waste into construction materials. Because our project is environmental friendly we preferred to use the method of pyrolysis where it works in a closed system at a desired temperature until the plastics get melted. We designed a prototype that match with this method where our drum will be working in the closed system, to make sure that no gas will be vaporized in the atmosphere if there is any.

In this research, we used high density polyethylene because of its excellent impact resistance, high tensile strength, low moisture absorption and chemical resistance properties.

\subsection{Material collection and preparations}

\subsubsection{Plastics}

Samples of high density polyethylene plastic wastes mostly bucket and jerry cans were collected from dumpsites in the University of Rwanda, Huye campus. They were thoroughly cleaned before use to ensure that the debris and other forms of impurities that could alter bonding of sand are removed. At the laboratory, the plastic samples were segmented into small particles.

In this research, we used high density polyethylene (HDPE) because of its excellent impact resistance, high tensile strength, low moisture absorption and chemical resistance properties.

\begin{tabular}{|l|l|l|l|l|}
\hline Property & Density & $\begin{array}{l}\text { Water } \\
\text { absorption }\end{array}$ & Tensile break & $\begin{array}{l}\text { Melting point } \\
\text { (in } \\
\text { OFFahrenheit }\end{array}$ \\
\hline
\end{tabular}




\begin{tabular}{|l|l|l|l|l|}
\hline & $\mathrm{g} / \mathrm{cm} 3$ & $\%$ & $\mathrm{psi}$ & degrees) \\
\hline HDPE & 59.88 & Sight & 4.423 & $259-267$ \\
& & & & \\
\hline
\end{tabular}

Table 1: Some of the properties of polymer used in the research

\subsubsection{Sand}

River sand was washed and dried before use in making the plastic and sand composite paving blocks. The sieve sizes used for particle size distribution were 10, 5, 2.36, $1.18 \mathrm{~mm}$ and $600,300,150$ and $75 \mu \mathrm{m}$; the sand used were retained on $1.18 \mathrm{~mm}$ sieve. This is done by shaker machine

\subsubsection{Plastic and sand mixing ratio}

For comparison purpose and quality check, three types of plastic and sand mixing ratio were used i.e. 1: 3, 1:4 and 1:5 (See Table ). Based on the mixing ratios, samples were then denoted as sp1, sp2 and sp3 respectively. The control sample is $\mathrm{C} 1$

\begin{tabular}{|l|l|l|l|l|l|l|}
\hline \multirow{2}{*}{ Sl. No. } & $\begin{array}{l}\text { Sample } \\
\text { designation }\end{array}$ & \multirow{2}{*}{$\begin{array}{l}\text { Mixing } \\
\text { ratio }\end{array}$} & \multicolumn{3}{|l|}{ Weight of material (g) } & \multicolumn{2}{|l|}{$\begin{array}{l}\text { Percentage of each } \\
\text { material in mixture }\end{array}$} \\
\cline { 4 - 7 } & & & HDPE & Sand & HDPE & Sand \\
\hline 1. & $\mathrm{C} 1$ & $1: 0$ & 3480 & 0 & 100 & 0 \\
\hline 2. & Sp1 & $1: 3$ & 870 & 2610 & 25 & 75 \\
\hline 3. & Sp2 & $1: 4$ & 696 & 2784 & 20 & 80 \\
\hline 4. & Sp3 & $1: 5$ & 580 & 2900 & 16.6 & 83.4 \\
\hline
\end{tabular}

Table 2: Plastic and sand mixing ratio

Melting process in a closed drum

A locally made metallic anaerobic reactor or a closed drum with a mixing device as shown in Figure 5 was manufactured. The mixing device helps to have a homogeneous mixture of plastic and sand.

\section{Compressive Test}

In order to determine the loading capacity of polyethylene and sand composite and also to evaluate the effects of sand on the compressive strength of HDPE, Compressive Test was carried out using hydraulic press machine tester as shown in Figure below7. Three samples per each percentage were tested and average strength determined by averaging the three results. The top surfaces against which the 
compressive strengths were to be measured were capped by cutting off any protruding parts. The following formula was used in calculating the compressive strength of the polyethylene and sand composite block.

Water Absorption test

A standard water absorption test was performed according to ASTM D750-95. It involved immersing three samples (that offers the highest compressive strength) in water for a period of 24 hours after weighing them with a weighing balance for dry weight determination.

Strength behavior after temperature

To determine the properties of pavers at elevated temperature, two pavers were heated in an incubator at a temperature of 35 degrees Celsius for 12 hours. We used both 35 degrees and 12 hours because they are the peak temperature in our region and the highest time of exposure to the sun respectively.

\section{Results and discussion}

The effect of temperature on plastics

In order to determine the melting point of plastic and subsequent effects of temperature on the mass of HDPE, different samples of the material were heated in a closed drum and their temperatures observed at 30 minutes interval. It was observed that HDPE melts at a temperature of 120-400 degrees Celsius.

Sand equivalent test

A higher sand equivalent value indicates that there is less clay-like material in a sample. Table 3 summarizes the result of the test.

\begin{tabular}{|l|l|l|l|l|l|}
\hline $\begin{array}{l}\text { Sl. } \\
\text { No. }\end{array}$ & $\begin{array}{l}\text { Shaking } \\
\text { time }(\mathrm{sec})\end{array}$ & $\begin{array}{l}\text { Initial } \\
\text { weight }(\mathrm{g})\end{array}$ & $\begin{array}{l}\text { Clay weight } \\
\mathrm{h} 1(\mathrm{~mm})\end{array}$ & $\begin{array}{l}\text { Sand height } \\
\mathrm{h} 2(\mathrm{~mm})\end{array}$ & $\begin{array}{l}\text { Sand. Equivalent } \\
\%\end{array}$ \\
\hline 1 & 30 & 129.8 & 137 & 109 & 80 \\
\hline
\end{tabular}

Table 3: Sand equivalent result

\subsection{Water absorption test}

The immersed pavers were removed from the water bath and dried naturally in air before measuring their saturated weights. The results were recorded in the table below:

\begin{tabular}{|l|l|l|l|l|}
\hline Sl.No. & $\begin{array}{l}\text { Dry weight } \\
\text { Wd }(\mathrm{g})\end{array}$ & $\begin{array}{l}\text { Saturated } \\
\text { weight Ws } \\
(\mathrm{g})\end{array}$ & $\begin{array}{l}\text { Change in mass }(\mathrm{g}) \\
\begin{array}{l}\text { Water absorption } \\
(\%)\end{array}\end{array}$ \\
\hline 1 & 1942.9 & 1943.7 & 0.8 & 0.041 \\
\hline 2 & 1894.0 & 1895.2 & 1.2 & 0.063 \\
\hline
\end{tabular}




\begin{tabular}{|l|l|l|l|l|}
\hline & & & & \\
\hline $\begin{array}{l}\text { Average } \\
\text { water } \\
\text { absorption }\end{array}$ & & & & 0.052 \\
\hline
\end{tabular}

Table 4: Results for water absorption test

As shown in Table 4, water absorption of high density polyethylene and sand composite is low. This is majorly because in normal circumstances, polyethylene registers water absorption of less than $0.02 \%$. As such, the low water absorption observed can only be attributed to the absence of pore formation because of compaction. Therefore, the research concludes that the paving blocks made of high density polyethylene and sand has higher performance in terms of water absorption compared to concrete ones that absorb relatively high amount of water with an average absorption of 5\% [12].

\subsection{Compressive strength test}

In this research two different compressive tests were carried out; one test was to determine the loading capacity of polyethylene and sand paver and other was to evaluate the change in loading capacity after exposure to temperature.

\subsubsection{Ordinary compressive strength}

All three types of ratio were tested one by one and average result was taken as paver's compressive strength. Two specimens of each ratio were tested. Results are shown in Table 5.

\begin{tabular}{|c|c|c|}
\hline Sample ratios (plastic: sand) & $\begin{array}{c}\text { Compressive strength } \\
(\mathrm{N} / \mathrm{mm} 2)\end{array}$ & $\begin{array}{l}\text { Average compressive strength } \\
(\mathrm{N} / \mathrm{mm} 2)\end{array}$ \\
\hline \multirow[t]{3}{*}{$1: 3$} & 21.65 & \multirow[t]{3}{*}{21.73} \\
\hline & 21.65 & \\
\hline & 21.91 & \\
\hline \multirow{3}{*}{$1: 4$} & 27.38 & \multirow{3}{*}{26.15} \\
\hline & 24.84 & \\
\hline & 26.24 & \\
\hline \multirow[t]{3}{*}{ 1:5 } & 4.45 & \multirow[t]{3}{*}{4.79} \\
\hline & 5.09 & \\
\hline & 4.84 & \\
\hline
\end{tabular}

Table 5: Compressive strength results

The table above shows impressive developments in mechanical qualities compared to cement and sand pavers. This actually, conforms to the findings of this research which indicate that mixture of sand and HDPE leads to improvement in compressive strength up to a given level before the strength begins to reduce as shown in Figure 8. 


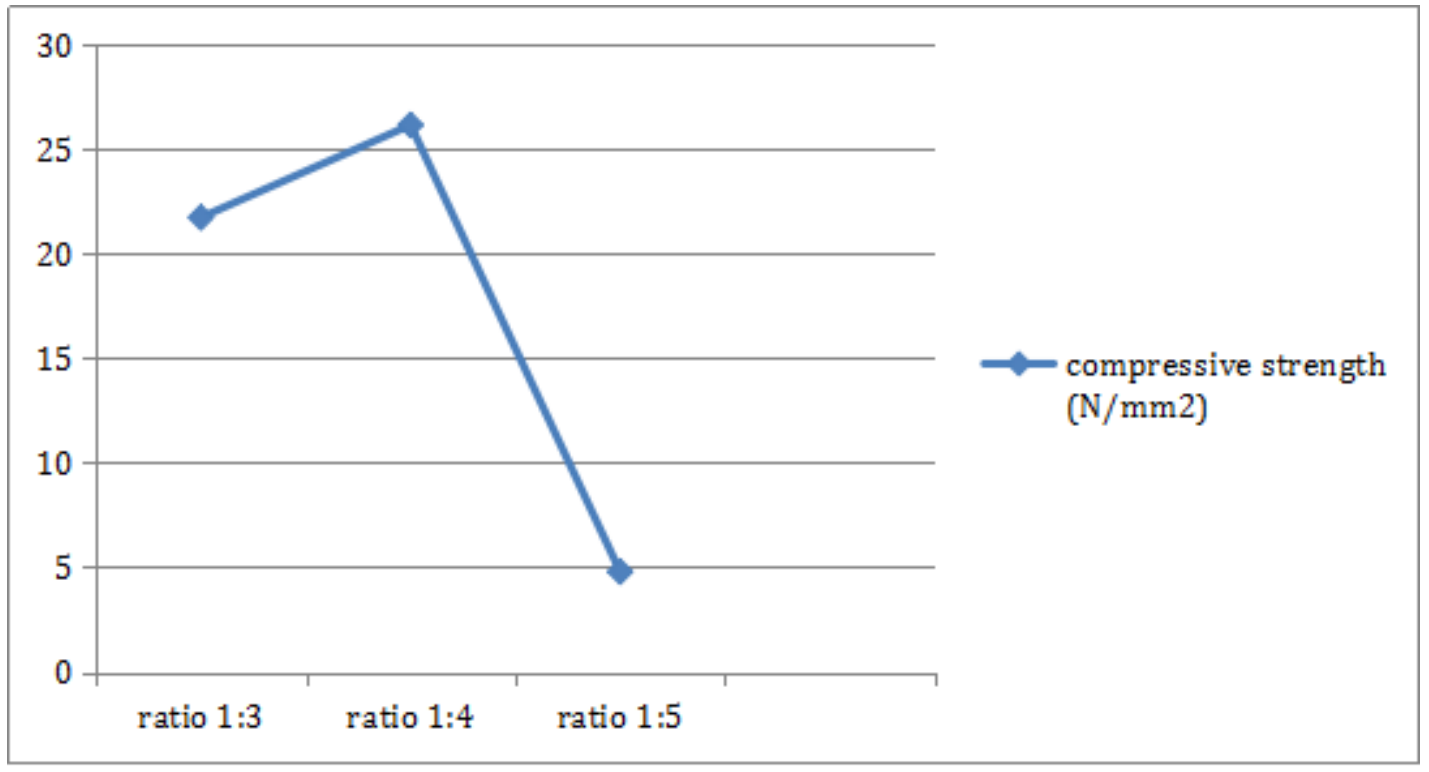

Figure 8: Compressive strength with respect to sand content

\section{Compressive strength after heat exposure}

The effect of temperature on compressive strength of paver's was tested after a constant heat exposure of 35 degrees Celsius in an oven for 24 hours. Results of this test are summarized in Table 6.

\begin{tabular}{|c|c|c|}
\hline $\begin{array}{l}\text { Sample ratios (plastic: } \\
\text { sand) }\end{array}$ & $\begin{array}{l}\text { Compressive strength } \\
(\mathrm{N} / \mathrm{mm} 2)\end{array}$ & $\begin{array}{l}\text { Average compressive } \\
\text { strength }(\mathrm{N} / \mathrm{mm} 2)\end{array}$ \\
\hline \multirow[t]{3}{*}{$1: 3$} & 17.83 & \multirow[t]{3}{*}{17.79} \\
\hline & 17.59 & \\
\hline & 17.96 & \\
\hline \multirow[t]{3}{*}{$1: 4$} & 23.18 & \multirow[t]{3}{*}{22.37} \\
\hline & 21.52 & \\
\hline & 22.42 & \\
\hline \multirow[t]{3}{*}{$1: 5$} & 3.56 & \multirow[t]{3}{*}{3.52} \\
\hline & 3.82 & \\
\hline & 3.18 & \\
\hline
\end{tabular}

Table 6: Compressive strength after heat exposure

The results as illustrated in Table 6 show that prolonged heat has influence on manufactured pavers. Variations of compressive strength before and after heat exposure are illustrated in Figure 9. 


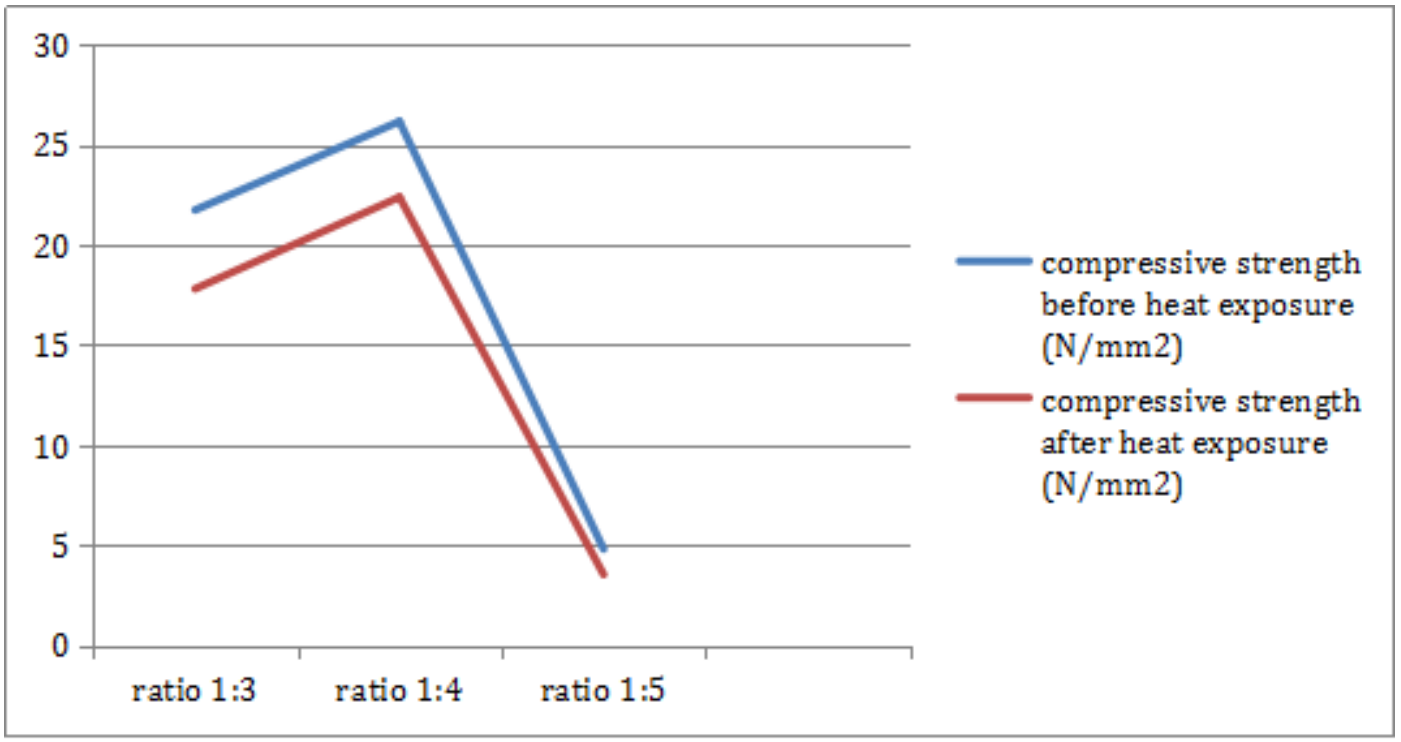

Figure 9: Variation of compressive strength with respect to temperature exposure

\subsubsection{Performance assessment}

From the compressive test results, strength of $26 \mathrm{~N} / \mathrm{mm} 2$ was recorded (sample $\mathrm{Sp} 2$ ) this strength meets the design standard requirement of concrete block paving. Owing to this observation, it can be concluded that the proposed paving blocks from this composite (polyethylene and sand) registers an impressive performance and can be applied in constructing residential streets and highways with lighter wheel loads.

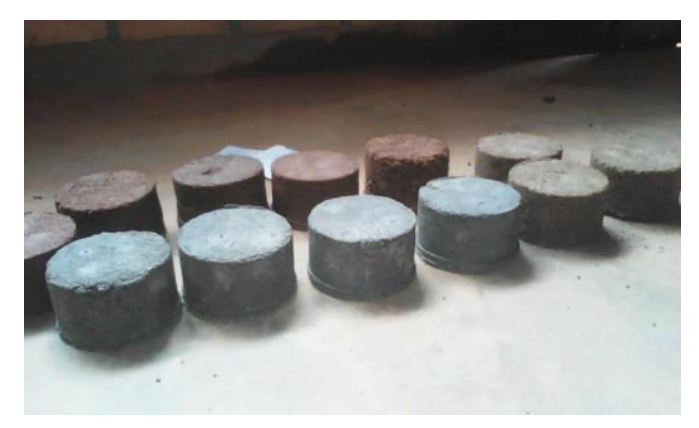

Figure 2: Pavers from plastic wastes and sand

Another important aspect that defines the performance of this kind of block is that it is not susceptible to spalling. In addition, blocks of polyethylene and sand have smooth and even edges (were it not shrinking). This smoothness and evenness of the edges creates a mechanism through which only very little, if no water at all, can reach the road foundation. Studies have revealed that the opposite is true in the case of concrete paving blocks that have uneven and rough edges [12] These characteristics of the polymer composite paving block can be highly useful in preventing or lowering possibility of surface rutting occurrence. As the smooth edges creates capillary forces that prevent water molecules from 
percolating in between the blocks, their evenness ensures closer and tighter packing thus resulting into lesser water percolation.

\section{Conclusion}

Fossil fuels are depleting at a tremendous rate than expected while roads are not just expensive, but also inefficient. Adding to that, plastics wastes are devastating to the environment. These challenges are not new, they are genuine engineering problems that have repeatedly occurred for many decades now and in the past. Highly challenging is the fact that solving these problems one by one can be very daunting and economically difficult. From the data collection analysis, it has been shown that paving materials made from high density polyethylene wastes and sand composite registers higher performance relative to the conventional one.

The plastic sand pavers possess more advantages which include cost efficiency, removal of wastes products thus abolishing the land requirement problem for dumping plastics. These pavers have important advantages over he heavier concrete and ceramic pavers as they are impervious to moisture, mildew fungus and other algae resistant; lighter in weight and eco-friendly.

If made and put into use, these Pavers will not only reduce construction costs especially those for repairs, but also assist in environmental conservation. Roads will be cheaply constructed, and with the increased durability, accessibility will be improved and economic growth bolstered.

In conclusion, this research achieved its objectives and, if applied in real life, it can help improve human life for plastic wastes management in the future.

\section{References}

[1] G. Scott, Polymers in modern life. Polymers and the Environment. The Royal Society of Chemistry, Cambridge. doi:10.1039/9781847551726-00001

[2]RM. Reddy, Impact of soil composting using municipal solid waste on biodegradation of plastics, Indian J. Biotechnol. 7 (2008) 235-239

[3] S. Awasthi, N. Srivastava, T. Singh, D. Tiwary, P. K. Mishra, Biodegradation of thermally treated low density polyethylene by fungus Rhizopus oryzae NS 5, 3 Biotech. 7 (2017) 1:73-83. doi: 10.1007/s13205-017-0699-4

[4] Y. Orhan, H. Buyukgungor, Enhancement of biodegradability of disposable polyethylene in controlled biological soil, Int. Biodeterior. Biodegrad. 45 (2000) 49-55. doi:10.1016/S09648305(00)00048-2. [Cross Ref]

[5] P. Nayak, A. Tiwari, Biodegradation of polyethylene and plastic by the help of microbial tools: a recent approach, IJBAR 2 (2011) 9: 344-355 
